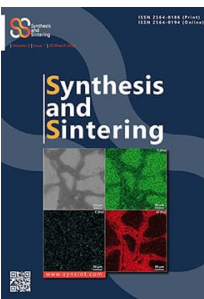

\title{
Synthesis and sintering of Fe-32Mn-6Si shape memory alloys prepared by mechanical alloying
}

\author{
Ali Shamsipoor ${ }^{\text {a }}$, Babak Mousavi ${ }^{\text {a }}$, Mohammad Sadegh Shakeri ${ }^{\text {b, } *}$ \\ ${ }^{a}$ Materials and Energy Research Center (MERC), P.O. Box 31779-83634, Karaj, Iran \\ ${ }^{b}$ Institute of Nuclear Physics Polish Academy of Sciences, PL-31342 Krakow, Poland
}

\section{A B S T R A C T}

Fe-32Mn-6Si alloy was produced using the mechanical alloying (MA) process of high purity powders under an inert argon gas atmosphere. The aim of this investigation is the in-depth study of the microstructure and phase transformation during the milling-sintering process of Fe-32Mn-6Si shape memory alloys. During the milling process, a significant amount of amorphous phase was created as well the crystalline martensite and austenite phases. The amorphous phase was increased by milling time enhancement and then it was decreased due to the mechano-crystalization phenomenon. It was detected that the microhardness of the alloyed powder directly depends on the amount of the amorphous phase. Furthermore, the particle size of as-milled powder firstly decreased and then increased, when the amorphous phase cojoined gradually during the milling process the transformation of martensite into austenite. The lattice strain was increased considerably during the milling process which was a reason for martensite phase creation resulting in the high shape memory properties. The amount of pre-strain for Fe$32 \mathrm{Mn}-6 \mathrm{Si}$ alloy was calculataed to be $3.3 \%$. Furthermore, the optimum sintering temperature was approved to be $950{ }^{\circ} \mathrm{C}$ by reduction of the percentage of pores and suitable densification.

\section{Introduction}

Shape memory alloys (SMAs) are materials that have the ability to recover their initial shape after subsequent heating and cooling process. These alloys are being used for various applications such as medical instruments, aerospace devices, and small mechanical systems. Recently, there has been considerable interest in Fe-Mn-Si Shape Memory alloys (SMAs) as a group of smart materials [1-3]. These group of material have unique properties such as appropriate shape memory effect (SME), cheap price, fine weldabillity, high corrosion resistance, excellent machinability and so on [4-8]. Because of these promising properties, Fe-Mn-Si alloy are being considered for mechanical engineering applications. The mentioned alloys have many applications in oil and gas industry, aerospace, and civil engineering due to suitable physical and mechanical properties [9-13].
KEYWORDS

Shape memory alloys

Mechanical alloying

Sintering

Phase transformation

Martensite

* Corresponding author. E-mail address: ms.shakeri@ifj.edu.pl (M.S. Shakeri)

Received 3 January 2022; Received in revised form 7 February 2022; Accepted 7 February 2022.

Peer review under responsibility of Synsint Research Group. This is an open access article under the CC BY license (https://creativecommons.org/licenses/by/4.0/). https://doi.org/10.53063/synsint.2022.2185 
influence of pre-rolling on Fe-Mn-Si properties [24]. They produced multiplicity of stacking faults by rolling and changed the properties, accordingly. Stanford and Dunne studied the influence of thermomechanical processing on shape memory effect of Fe-Mn-Si based alloys $[25,26]$. They showed thermomechanical path has a great effect on recrystallization process. Balagurov et al investigated the thermocycling influence on structure of Fe-Mn-Si alloys [27]. They had shown that thermocycles raise the microstrains which are the centers for martensite nucleation. It is noticeable that although MA is a simple and effective method for synthesizing, it is rarely used for synthesizing Fe-Mn-Si shape memory alloy. Saito et al. produced FeMn-Si SMA by MA method and investigated the phase transformation as same as sintering process of this alloy [18]. Furthermore, Liu et al investigated mechanical alloying of Fe-Mn-Si system [28]. They investigated the effect of milling parameters on phase formation in this alloy.

Fe-Mn-Si groups are low cost SMAs in compare with other materials like NiTi. Mechanical alloying could also reduce the cost of final product. By the way, the high cost of SMAs has limited the application of them in structural engineering [29]. The aim of this investigation is the production of Fe-32Mn-6Si SMA with comparible properties with conventional SMAs. The reason for chosing Fe-32Mn-6Si as a preferred composition is the high and good shape memory properties among other compositions of this alloy [30]. In the present investigation it has been tried to produce the amorphous/nanocrystalline Fe-32Mn-6Si SMA using mechanical alloying technique under argon atmosphere. The microstructure, thermal, and SME properties of this alloy have been also investigated, thoroughly.

\section{Experimental Procedure}

\subsection{Milling process}

High purity (> 99\%) Fe, Mn and Si powders (Sigma-Aldrich) with particle size of $150 \mu \mathrm{m}$ were used as raw materials for synthesizing Fe$32 \mathrm{Mn}-6 \mathrm{Si}$ shape memory alloy. The amount of each powder was 6.2 $\mathrm{wt} \%, 3.2 \mathrm{wt} \%$ and $0.6 \mathrm{wt} \%$, respectively. The alloying procedure was accomplished in planetary ball mill. The detailed of ball milling process can be found in Ref. [30].

\subsection{Sintering procedure}

The alloyed powder was uniaxially cold pressed to cylinder shape with $7 \mathrm{~mm}$ diameter and $1 \mathrm{~mm}$ thickness at compressive pressure of 800 MPa. The dilatometer (DIL 402C) was used for determination of suitable sintering temperature by dimensional change in the sample at non-isothermal sintering. The heating rate of dilatometry is $20^{\circ} \mathrm{C} / \mathrm{min}$ in argon atmosphere. For the evaluation of sintering temperature, samples were sintered under argon atmosphere at 850,900 and $950{ }^{\circ} \mathrm{C}$ for $6 \mathrm{~h}$. Furthermore, the sintering time was evaluated at $950{ }^{\circ} \mathrm{C}$ for 10 min, $12 \mathrm{~h}$, and $24 \mathrm{~h}$. An optical microscope (Olympus BX Series) was used for investigation of the effect of sintering time and temperature on densification. Furthermore, the percentage of porosity was measured by material plus software according to the ASTM B 276 standard. To investigate the micro hardness changes, differently milled samples sintered at $950{ }^{\circ} \mathrm{C}$ for $12 \mathrm{~h}$ were utilized. Furthermore, $300 \mathrm{gr}$ load was applied by Vickers indenter for $10 \mathrm{~s}$ (Microhardness Koopa, Iran). It should be mentioned that samples were polished before the test.

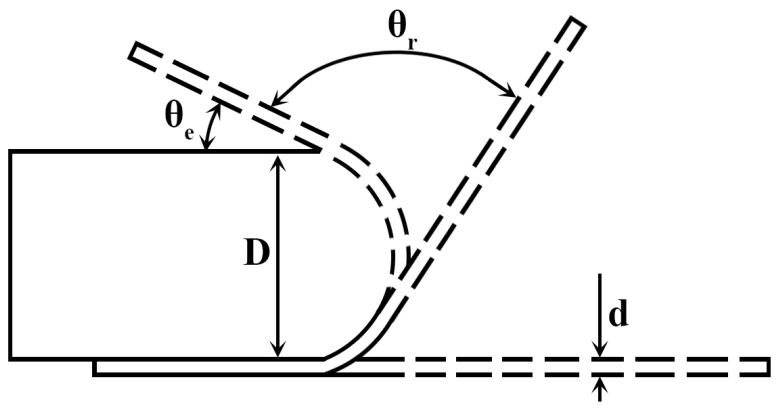

Fig. 1. Schematic illustration of the bending test for SME evaluation.

\subsection{Microstructural analysis}

For the investigation of chemical composition of as-milled powders, the X-ray Fluorescence (XRF, PHILIPS, PW2400) was utilized and then the PAN analytical software was used to calculate to analyse the results. The structural property and also phase transformation was identified by X-ray Diffraction (XRD, Bruker Advance 2, CuKa1, 2 radiations) method. The thermal stability of the powders was also investigated by a Differential Thermal Analysis (DTA, NETZSCH, STA 449C Jupiter) under a pure argon gas. The morphological change and elemental mapping images of the powder particles was evaluated by a Scanning Electron Microscopy (SEM, JEOL-JSM 5310) and also the local phase composition of powders was checked by Energy Dispersive Spectroscopy (EDS). Finally, the designated particles were distributed in ethanol, dropped down to a copper grid, and then were studied by a high resolution Transmission Electron Microscope (HRTEM, FEI, Tecnai G2 F30) in the bright-field mode.

\subsection{Shape memory effect (SME)}

The SME was evaluated by bending the strip-shape specimens with 1 $\mathrm{mm}$ thickness which was sintered at $950{ }^{\circ} \mathrm{C}$ for $12 \mathrm{~h}$ and then quenched

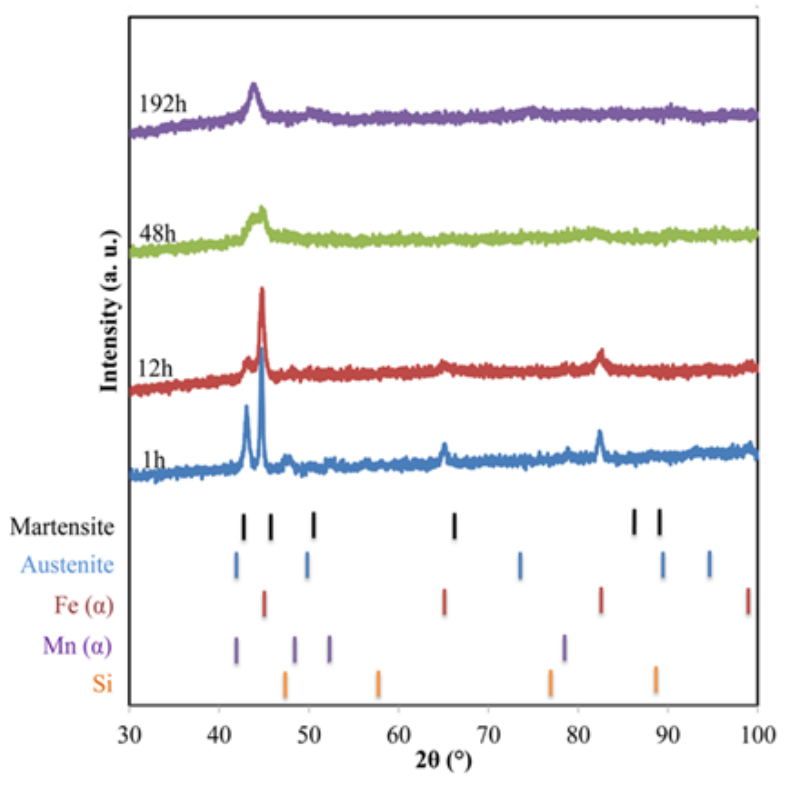

Fig. 2. The XRD pattern of as-milled powders at various milling times. 


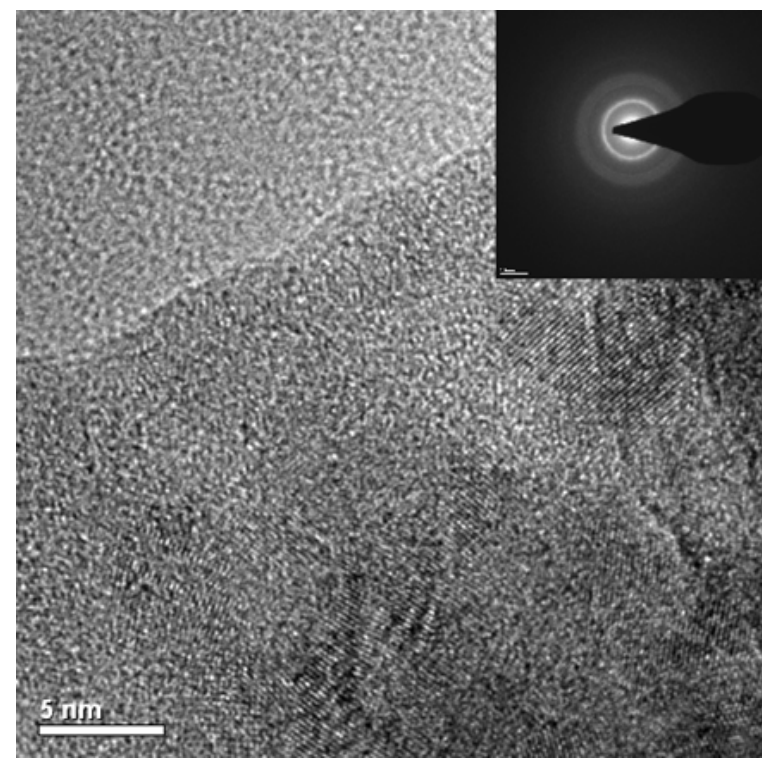

Fig. 3. The HRTEM of the milled specimen for $96 \mathrm{~h}$.

in cold water. The specimens were malformed at room temperature by bending over a mandrel. The pre-strain was calculated by Eq. 1 [4],

$\varepsilon=\frac{\mathrm{d}}{\mathrm{D}}$

In this equation, $\mathrm{D}$ is bending diameter $(30 \mathrm{~mm})$ and $\mathrm{d}$ is sample thickness $(1 \mathrm{~mm})$. After pre-deformation, elastic behavior of samples was identified by measurement of $\theta_{\mathrm{e}}$ angle [4]. Once the pre-strained specimens warmed up for $10 \mathrm{~min}$ at $400{ }^{\circ} \mathrm{C}$, the shape recovery value was found out after heating the. Then SME factor $(\eta)$ was calculated by Eq. 2 [20],

$\eta=\left(\frac{\theta_{\mathrm{r}}}{180-\theta_{\varepsilon}}\right) \times 100 \%$

Here $\theta_{\mathrm{r}}$ is shape recovery angle. Fig. 1 shows the schematic of evaluation of shape memory property.

\section{Results and discussion}

\subsection{Microstructural evaluation}

The chemical composition of the sample at maximum milling time $(192 \mathrm{~h})$ is shown in Table 1. The obtained chemical composition showed that the mechanical alloying parameters were right and acceptable.

The structural evaluation of the as-milled powders at various milling times are shown in Fig. 2. As it can be seen, at early stage of milling

Table 1. The chemical composition of $192 \mathrm{~h}$ milled powders.

\begin{tabular}{|c|c|c|c|c|c|c|}
\hline \multirow{3}{*}{$\begin{array}{c}\text { Milling } \\
\text { time } \\
\text { (h) }\end{array}$} & \multicolumn{6}{|c|}{ Weight percentage (\%) } \\
\hline & \multicolumn{2}{|c|}{$\mathrm{Fe}$} & \multicolumn{2}{|c|}{$\mathrm{Mn}$} & \multicolumn{2}{|c|}{$\mathrm{Si}$} \\
\hline & Con* & $\mathrm{AE}^{* *}$ & Con & $\mathrm{AE}$ & Con & $\mathrm{AE}$ \\
\hline 192 & 62.48 & 0.05 & 31.78 & 0.03 & 5.74 & 0.02 \\
\hline
\end{tabular}

*Con: concentration, ${ }^{* *} \mathrm{AE}$ : absolute error
Table 2. The quantitative phase analysis of samples after different milling times.

\begin{tabular}{ccccccc}
\hline $\begin{array}{c}\text { Milling } \\
\text { time } \\
\text { (h) }\end{array}$ & \multicolumn{6}{c}{ Phase percentage (\%) } \\
\cline { 2 - 7 } & $\mathrm{Fe}$ & $\mathrm{Mn}$ & $\mathrm{Si}$ & Austenite & Martensite & Amorphous \\
\hline 1 & 71 & 23.4 & 5.6 & 0 & 0 & 0 \\
\hline 24 & 31 & 4 & 0 & 5 & 0 & 60 \\
\hline 48 & 10 & 0 & 0 & 9 & 0 & 81 \\
\hline 96 & 0 & 0 & 0 & 18 & 24 & 58 \\
\hline
\end{tabular}

time $(1 \mathrm{~h})$, the diffractions of powders contain Fe (Body Centered Cubic (BCC)), Mn and Si. By increasing the time of milling process, sharpness of peaks is reduced and the peaks' broadening are enhanced. It means that the newly created crystallite sizes are decreased and the strain of lattice is increased.

It has to be mentioned that the control of chemical compostition during mechanical alloyng process is vital due to the prevention of impurities into the mixture. Our results showed that stoichiometric ratio of the alloy remains constant after ball-milling. The probable impurities are $\mathrm{Fe}, \mathrm{O}$ and $\mathrm{Cr}$ which were not found after analyzing with XRF. Furthermore, oxygen impurity was controlled during process with $\mathrm{Ar}$ blasting.

Structural defects such as vacancies, dislocations etc, are widely created because of drastic plastic deformation throughout milling process and consequently the strain energy levels and disordering of the phases are increased. Under these conditions, the new crystalline phases can be formed from the previous phases with different structures or as an amorphous phase. Accordingly, FCC austenite phase as well as amorphous phase is created during milling process development. XRD peak broadening is considerably increased after 48 $\mathrm{h}$ of milling. Therefore, XRD profile becomes hallo and the high angle peaks are diminished. As it is illustrated, the sharpness of XRD peaks is increased with the increment of the milling time which is a reason for mechano-crystallization of the amorphous phase.

As it was mentioned, the mechano-crystallization will occurred with increasing the milling time because of increasing the temperature during the process. The quantity of amorphous phases was calculated using the Riteveld refienemnet of the XRD results as shown in Table 2. The stress induced Martensite is formed by creation and overlapping of the stacking faults at higher milling times. Moreover, the crystallographic data such as lattice constants and space groups of available phases calculated by Xpert software are illusterated in the Table 3.

As a result, the final product contains amorphous and crystalline (Martensite and Austenite) phases which are confirmed by the high

Table 3. The crystallographic data of phases.

\begin{tabular}{cccc}
\hline Phases & Symmetry & Space group & Lattice constant \\
\hline $\mathrm{Fe}(\alpha)$ & Cubic & $\mathrm{Im}-3 \mathrm{~m}$ & $\mathrm{a}_{0}=2.945$ \\
\hline $\mathrm{Mn}(\alpha)$ & Cubic & $\mathrm{I}-43 \mathrm{~m}$ & $\mathrm{a}_{0}=8.94$ \\
\hline $\mathrm{Si}(\mathrm{hcp})$ & Hexagonal & $\mathrm{P} 6 / \mathrm{mmm}$ & $\mathrm{a}=2.62, \mathrm{c}=2.48$ \\
\hline$\gamma$ & Cubic & $\mathrm{Fm} 3 \mathrm{~m}$ & $\mathrm{a}=3.8$ \\
\hline Martensite & Hexagonal & $\mathrm{P} 63 / \mathrm{mmc}$ & $\mathrm{A}=2.54, \mathrm{c}=3.91$ \\
\hline
\end{tabular}



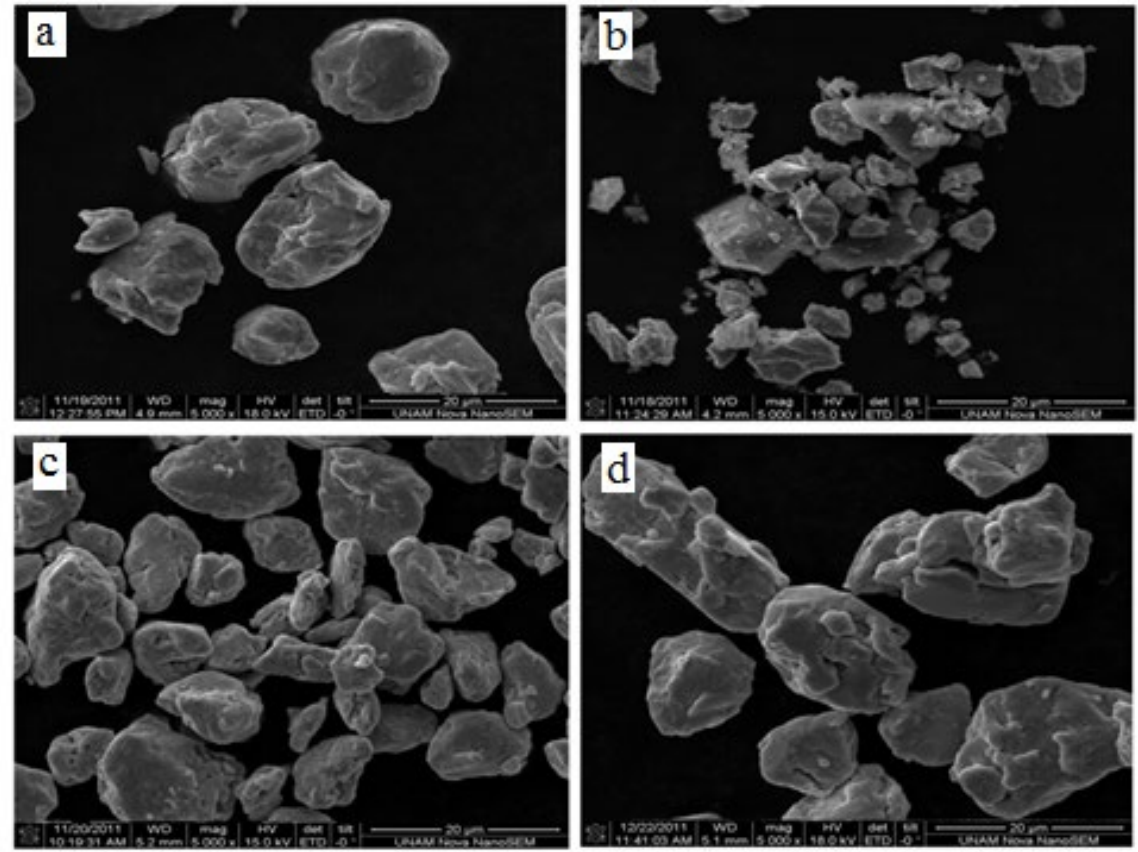

Fig. 4. The SEM images of the as-milled sample at various milling times, a) $1 \mathrm{~h}, \mathrm{~b}) 24 \mathrm{~h}$, c) $48 \mathrm{~h}$ and d) $96 \mathrm{~h}$.

resolution TEM image and the corresponding Selected Area Diffraction (SAD) pattern in Fig. 3.

The powder morphology and particle size of the as-milled powders according to the length milling of process was studied by SEM micrograph as it is illustrated in Fig. 4. At the early stages of milling, the process includes fracturing of particles. The average particle size is $5-20 \mu \mathrm{m}$ and also the morphology is plate like. After $24 \mathrm{~h}$ of MA process, the brittleness of powder particles is increased and then the particle size is noticeably reduced due to enhancement of the percentage of amorphous phase according to XRD results. As a result, their morphology tends toward the spherical shape. At higher milling times, the cold welding process overcame the fracture mechanism because of the transition of amorphous phase to the crystalline phases, i.e. increasing the ductility of powder particles. Hence, size of powder particles is increased with an irregular morphology.

The distribution of the chemical composition of the powder mixtures at $1 \mathrm{~h}$ and $192 \mathrm{~h}$ of milling process was studied using the elemental images mapping as it is illustrated in Fig. 5. Fig. 5a shows the elemental mapping of powder after $1 \mathrm{~h}$ milling process. Heterogeneous distribution of elements is clear in the figures illustrating the suitable
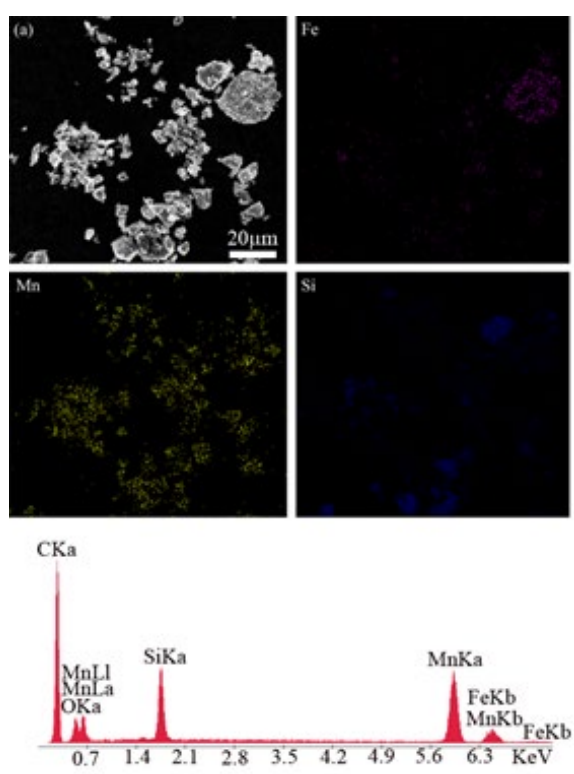
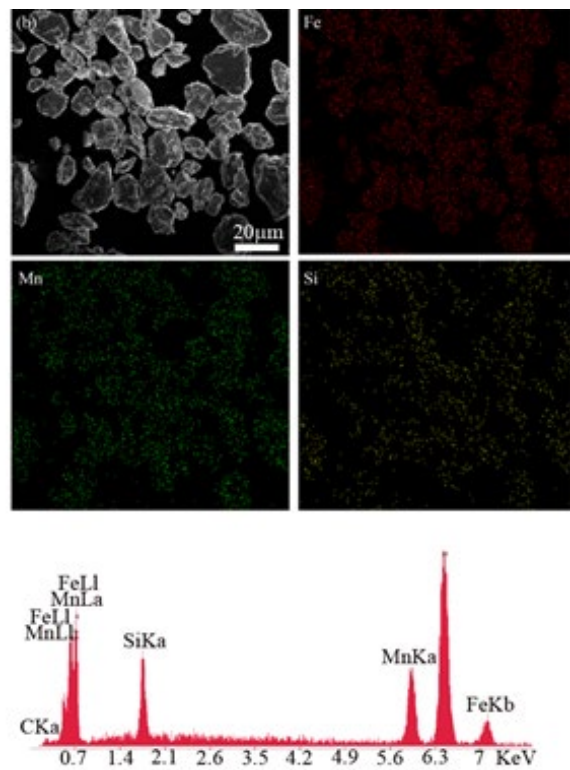

Fig. 5. The distribution of the chemical composition of the powder mixtures at a) $1 \mathrm{~h}$ and b) $192 \mathrm{~h}$ of milling process. 


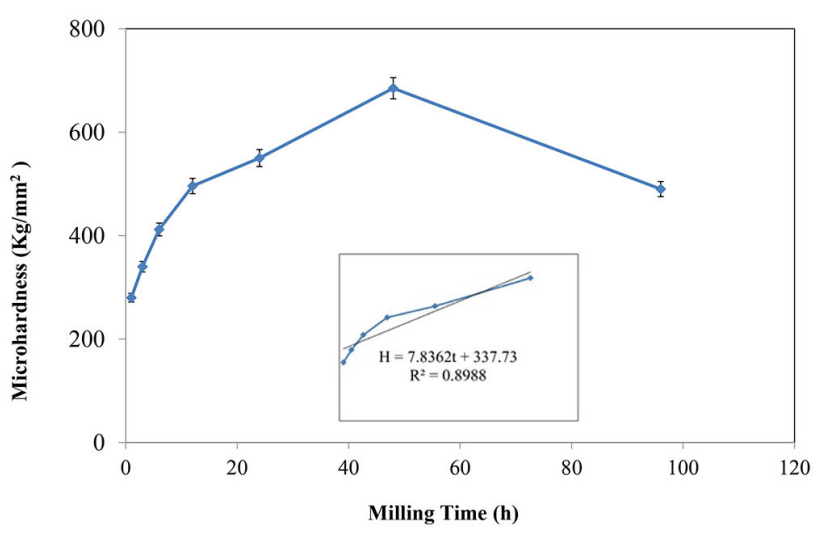

Fig. 6. The variation of the hardness as a function of milling time for samples sintered at $950^{\circ} \mathrm{C}$ for $12 \mathrm{~h}$.

role of MA process. Fig. $5 \mathrm{~b}$ shows the elemental mapping of powder after $192 \mathrm{~h}$ of milling process. Homogeneous distribution of elements is the keypoint of the mapping images illustrating the formation of different phases.

\subsection{Mechanical properties}

The micro hardness evalution of samples milled for different times and sintered at $950{ }^{\circ} \mathrm{C}$ for $12 \mathrm{~h}$, is shown in Fig. 6. As it can be seen, the micro hardness is increased with the milling time progress up to $48 \mathrm{~h}$ due to the creation of amorphous phase which is brittle and hard. Moreover, micro hardness is decreased by more development of milling process, due to occurrence of mechano-crystallization and formation of crystalline ductile phases.

Benjamin and Volin showed that the hardness is a linear function of milling time until the raw material exists [19]. The inter layer thickness can be calculated by Eq. 3 and 4 .

$\mathrm{H}=\mathrm{A}+\mathrm{Bt}$

Where, $\mathrm{H}$ and $\mathrm{t}$ are the Vickers' hardness and milling time, respectively.

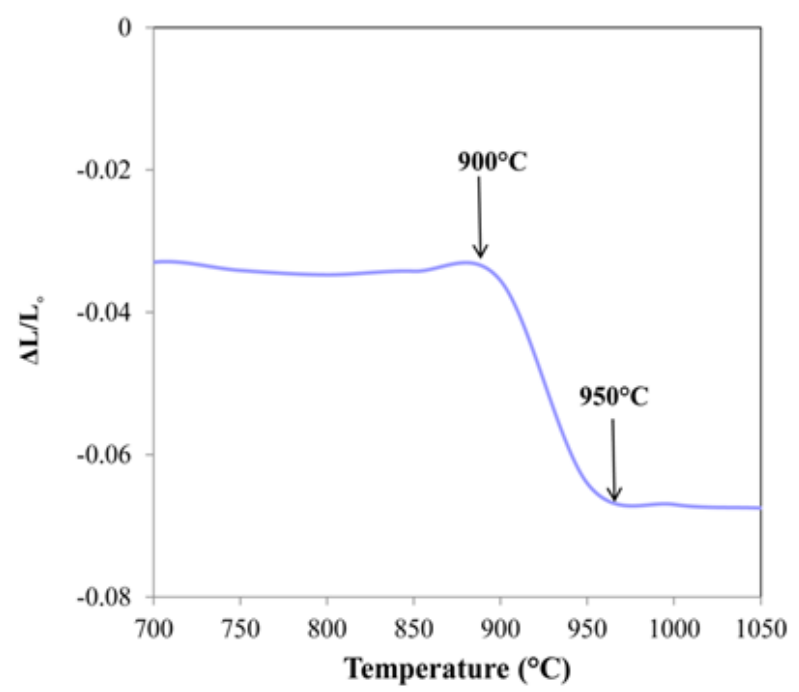

Fig. 7. Dilatometric diagram of the sintered powder milled for $96 \mathrm{~h}$.

$\operatorname{Ln}\left(\frac{\mathrm{L}_{0}}{\mathrm{~L}_{\mathrm{t}}}\right)=\frac{\mathrm{K}}{\mathrm{B}} \operatorname{Ln}\left[1+\left(\frac{\mathrm{B}}{\mathrm{A}}\right) \mathrm{t}\right]$

Where $\mathrm{K}, \mathrm{A}$, and $\mathrm{B}$ are constants and $\mathrm{L}$ symbolizes the lamellar thickness. The quantity of $\mathrm{L}_{0}$ (average particle size) and $\mathrm{L}_{\mathrm{t}}$ (thickness of layer) are calculated from Fig. 5 where $\mathrm{L}_{0}$ and $\mathrm{L}_{\mathrm{t}}$ are $25 \mu \mathrm{m}$ and 4.1 $\mu \mathrm{m}$, respectively. By attention to Fig. 5, A, B and $\mathrm{K}$ constants are equal to $337.73,7.8$ and 612 , respectively. Furthermore, the calculated layer thicknesses are $4100 \mathrm{~nm}, 158 \mathrm{~nm}$ and $19 \mathrm{~nm}$ after 1, 24 and $48 \mathrm{~h}$ milling times, respectively .it is clear that by the progress of milling process, the layer thickness is decreased and the alloying process was completed at sufficient milling time.

\subsection{Sintering process}

The sintering process is a crucial stage in powder metallurgy process

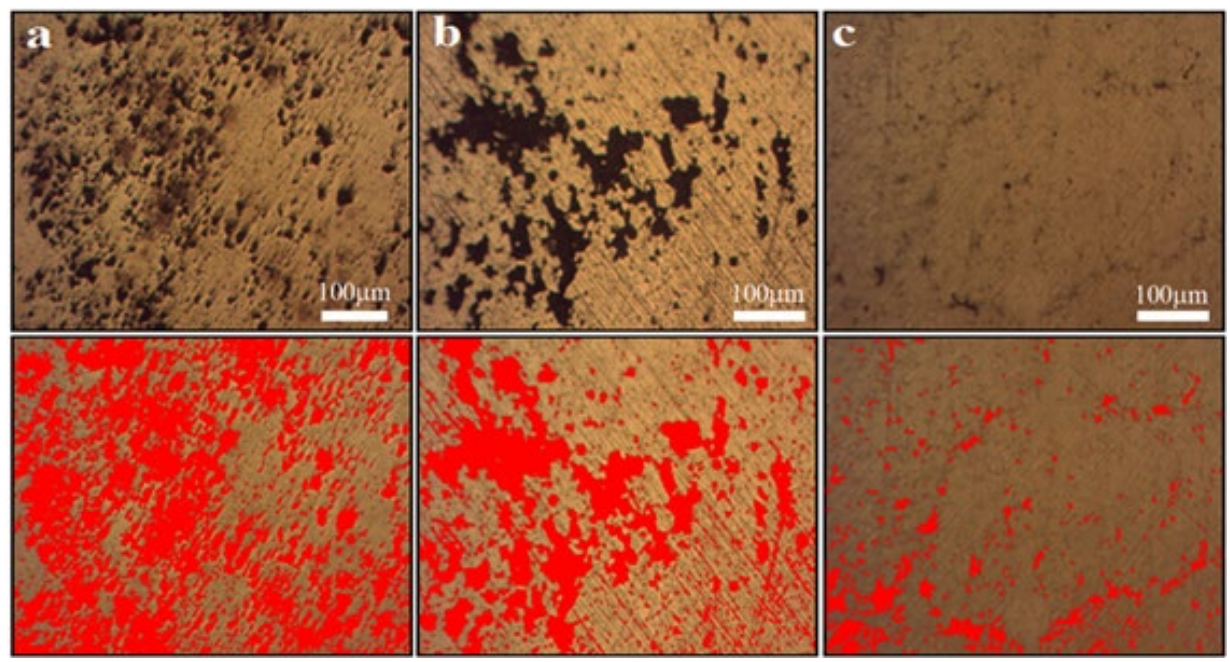

Fig. 8. The optical micrograph of the sintered samples at a) 850 , b) 900 , and c) $950{ }^{\circ} \mathrm{C}$ for $6 \mathrm{~h}$. 


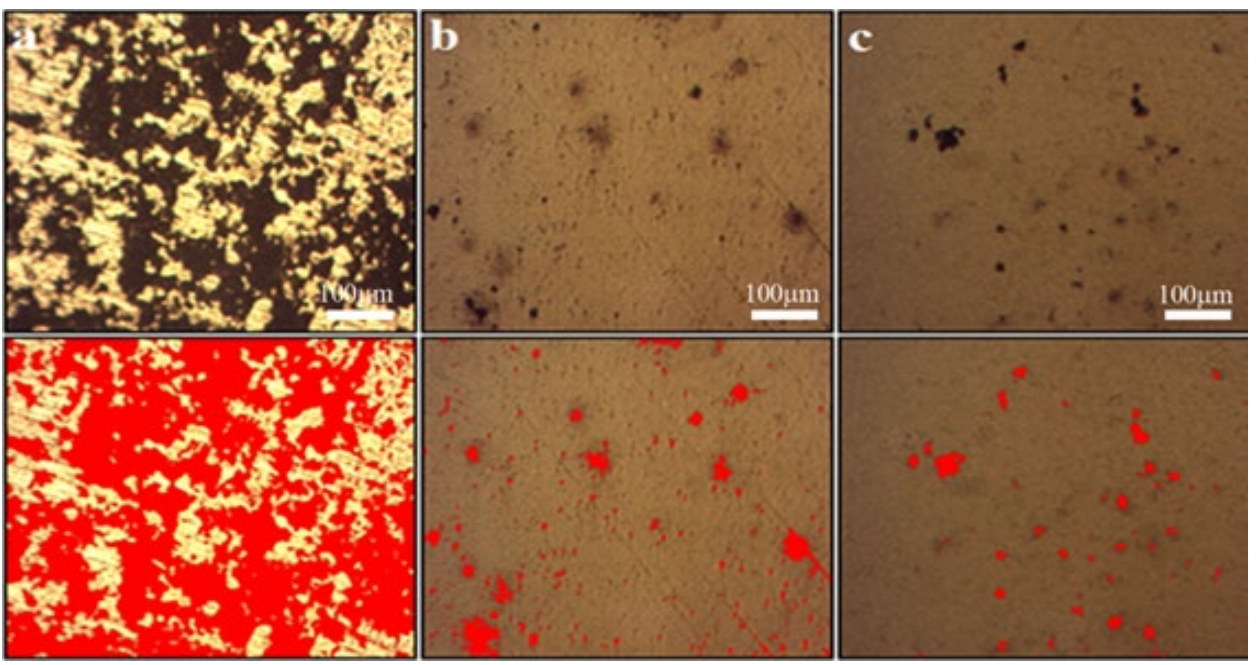

Fig. 9. The optical micrograph of the sintered samples at $950{ }^{\circ} \mathrm{C}$ for a) $10 \mathrm{~min}$, b) $12 \mathrm{~h}$, and c) $24 \mathrm{~h}$.

and usually goes along with variations such as changes in grain size and shape [31]. This process is accompanied by volume change. By sintering the samples at suitable temperature, the powder densification is feasible. The appropriate temperature for sintering a powder can be obtained by measurement of the dimensional changes in dilatometry test. Fig. 7 exhibits the dilatometric curve of sintered sample milled for $96 \mathrm{~h}$ at various sintering temperatures. As it can be seen in Fig. 6, a drastic decrease in shrinkage of sample has occurred at $900-950{ }^{\circ} \mathrm{C}$ and the proper densification is obtained at $950{ }^{\circ} \mathrm{C}$.

The optical microscope was used for investigation of sintered powders which were milled for $96 \mathrm{~h}$. The effect of sintering temperature and time on microstructure of samples are displayed in Fig. 8 and Fig. 9, respectively. The image analyzer software is utilized for investigation of optical images according to the ASTM B 276 standard.

According to the results, it is quite obvious that by increasing the sintering time, the percentage of porosity is decreased and the density of samples is increased. By increasing the sintering time, the pores tend to be isolated and their spherical shape turns toward being as irregular shapes. The percentage of porosity in all samples is listed in Table 4 .

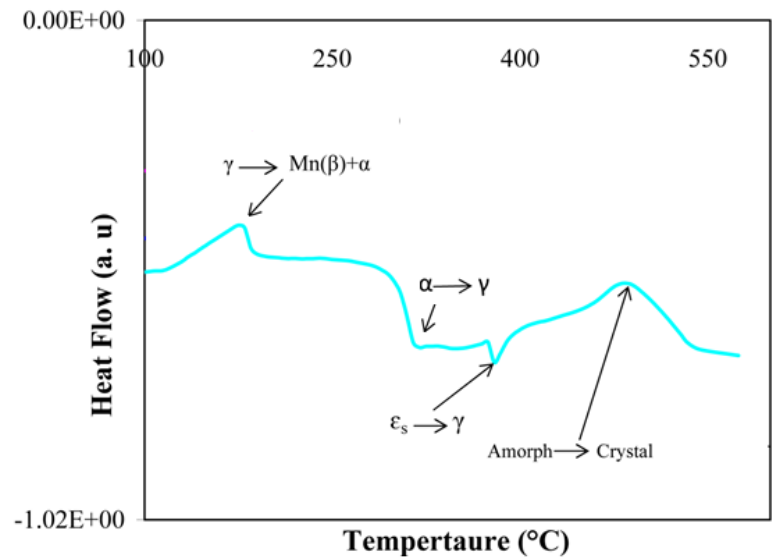

Fig. 10. DTA profiles for as-milled powders at different milling times.
In order to study the structural variations of as-milled powders during sintering heat treatment, thermal analysis (DTA) with constant heating rate of $20 \mathrm{~K} / \mathrm{min}$ was used as it is illustrated in Fig. 10.

To determine the origin of transition peaks, the samples were heated well below and above the peaks' temperatures and afterward the XRD analyses were executed for all samples at ambient temperature. Fig. 11 exhibit the XRD patterns of the sample milled for $96 \mathrm{~h}$ and heat treated in different temperatures for determining the phase transformations.

As it can be observed, the first exothermic peak at $180{ }^{\circ} \mathrm{C}$ indicates the $\gamma$-phase transformed to ferrite and $\beta$-Mn phases. The endothermic peak at $310{ }^{\circ} \mathrm{C}$ corresponds to the $\alpha$-to- $\gamma$ transformation which is confirmed by Fe-Mn-Si phase diagram. According to the XRD results it can be concluded that the endothermic peak at $380{ }^{\circ} \mathrm{C}$ indicates the transformation temperature of the stress induced Martensite (Hexagonal closet packed (hcp) structure) to austenite (fcc structure) phase. The second exothermic peak at $470{ }^{\circ} \mathrm{C}$ shows that the amorphous phase was transformed to the crystalline phase and the recrystallization has occurred. It is obvious that by increasing the milling time, mechano-crystallization is occurred at higher temperatures and crystallization peak shift to higher temperatures in DTA test. Also, by progression of the process, the peak is sharper and this shows that the quantity, amorphous phase became more stable and homogen until reach to maximum value at $48 \mathrm{~h}$ of milling process. At higher milling times, amorphous phase is transformed to the crystalline phase and the crystallization peak is broadened.

Table 4. The percentage of porosity in all sintered samples.

\begin{tabular}{ccc}
\hline $\begin{array}{c}\text { Sintering } \\
\text { temperature }\left({ }^{\circ} \mathbf{C}\right)\end{array}$ & $\begin{array}{c}\text { Sintering time } \\
(\mathbf{m i n})\end{array}$ & $\begin{array}{c}\text { Porosity } \\
(\mathbf{\%})\end{array}$ \\
\hline 850 & 360 & 52.62 \\
\hline 900 & 360 & 33.898 \\
\hline 950 & 360 & 9.57 \\
\hline 950 & 10 & 79.82 \\
\hline 950 & 720 & 4.57 \\
\hline 950 & 1440 & 1.85 \\
\hline
\end{tabular}




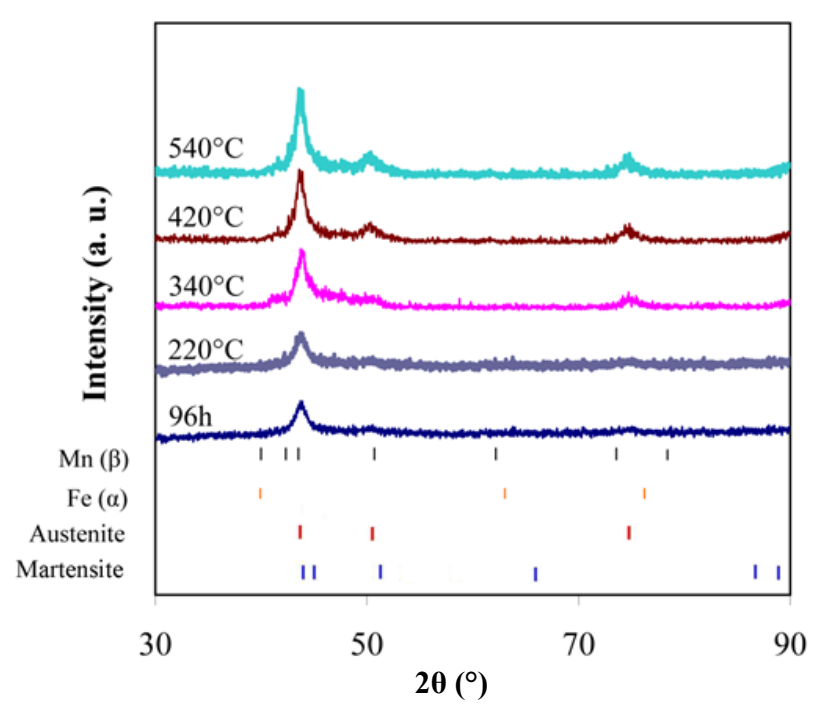

Fig. 11. XRD patterns of the samples milled for $96 \mathrm{~h}$ and heat treated at $220,340,420$ and $540 \mathrm{~K}$.

\subsection{Shape memory results}

Using the Eq. 1, the amount of pre-strain was calcultaed to be $3.3 \%$. The quantity of shape recovery was ascertained after heating the prestrained samples for $10 \mathrm{~min}$ at the $400{ }^{\circ} \mathrm{C}$. The results of the SME measurements including SME factor $(\eta)$, shape recovery angle $(\theta \mathrm{r})$ and $\theta \mathrm{e}$ are $60 \%, 102$ and 10 , respectively. The formation of stress induced martensite $(\varepsilon, h c p)$ from parent austenite phase $(\gamma, \mathrm{fcc})$ and the inverse transformation $(\gamma$ to $\varepsilon$ ) throughout the heating cycle are the main reason of SME in this alloying system [2-5]. This non-thermoelastic or semithermoelastic conversion was occurred by the creation of stacking faults (SFs) because of the movement of the Shockley partial

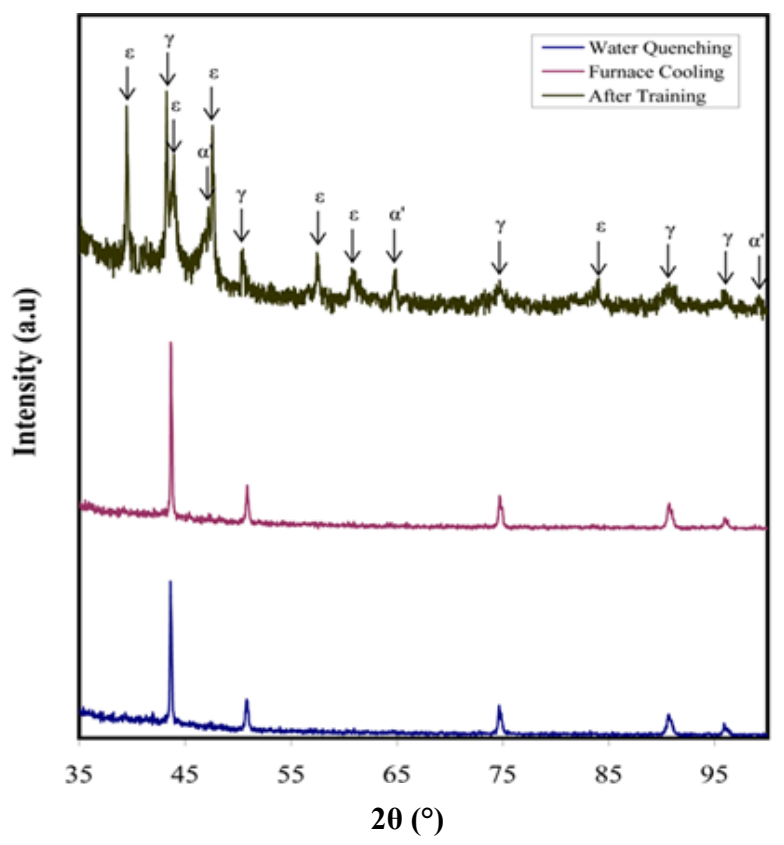

Fig. 12. The XRD patterns of the samples cooled in the furnace, quenched in cold water and cold worked after quenching. dislocations $(a \gamma / 6<112>)$ in the parent phase. Actually, SFs are suitable area for nucleation of the martensite phase. After that, the $\varepsilon$-phase can be formed by their overlap [4].

Fig. 12 shows XRD pattern of Fe-32Mn-6Si sample milled for $96 \mathrm{~h}$ and sintered at $950{ }^{\circ} \mathrm{C}$ for three samples cooling in furnace, quenching in cold water and cold working by bending the strip-shape specimens with $1 \mathrm{~mm}$ thickness and $30 \mathrm{~mm}$ diameter of bending. According to Fig. 12, the samples that were cooled at furnace and quenched at cold water only contain austenite phase. The thermal martensite phase cannot be formed in the sample which was quenched in cold water because of the $\mathrm{M}_{\mathrm{s}}$ temperature(Austenite to martensite transformation start temperature) in this alloy was lower than $0{ }^{\circ} \mathrm{C}$. As is illustrated, by applying the cold work, the stress induced martensite $(\varepsilon)$ was produced extensively which means that the sample could show SME due to stress induced martensite transformation. Actually, the SME in this alloying system is usually created by stress induced martensite formation. According to the XRD pattern, the $\alpha^{\prime}$ martensite is also produced in low quantity.The formation of the $\alpha^{\prime}$ phase can impede the reverse motion of the shockley partial dislocations and can decrease the SME properties of the sample.

\section{Conclusions}

The high energy ball milling under argon atmosphere was used for synthesizing Fe-32Mn-6Si shape memory alloy. At early stage of milling process, the elemental powders join together. Then, the amorphous phase initiated and then received to maximum value and finally, the mechano-crystallization of the amorphous phase occurred (Transformation of the $\alpha$-phase to $\gamma$-phase). The martensite phase ( $\varepsilon$ hcp) began to form with the progression of the process. By progression of milling process, the morphology of the powders was changed from plate like to semi-sphere and then from semi-sphere to irregular shape. The crystallite size of as-milled powders reduced to nanometric levels. On the other hand, the lattice strain was increased considerably by milling evolution. Furthermore, the micro hardness of the as-milled powder increases by increasing the amorphous phase and then reduced by mechano-crystallization effect. A considerable amount of stress induced martensite phase (as SME properties) was observed in the sample after cold working. SME was illustrated due to the formation of $\varepsilon$-Hcp from $\gamma$-Fcc and the reverse transformation ( $\varepsilon$ to $\gamma$ ) during the heating cycle.

\section{References}

[1] Y.H. Wen, N. Li, L.R. Xiong, Composition design principles for Fe$\mathrm{Mn}-\mathrm{Si}-\mathrm{Cr}-\mathrm{Ni}$ based alloys with better shape memory effect and higher recovery stress, Mater. Sci. Eng. 407 (2005) 31-35. https://doi.org/ 10.1016/j.msea.2005.08.054.

[2] A. Sato, E. Chishima, K.Soma, T.Mori, Physical properties controlling shape memory effect in Fe-Mn-Si alloys, Act Metal. 34 (1986) 287-294. https://doi.org/10.1016/0001-6160(86)90199-9.

[3] N. Stanford, D.P. Dunne, Effect of second-phase particles on shape memory in Fe-Mn-Si-based alloys, Mater Sci Eng. 454-455 (2007) 407-415. https://doi.org/10.1016/j.msea.2006.11.084.

[4] Y.H. Wen, M. Yan, N. Li, Effects of carbon addition and aging on the shape memory effect of $\mathrm{Fe}-\mathrm{Mn}-\mathrm{Si}-\mathrm{Cr}-\mathrm{Ni}$ alloys, Scripta Mater. 50 (2004) 441-444. https://doi.org/10.1016/j.scriptamat.2003.11.008.

[5] B. Pricop, U. Soyler, R. I. Comneci, B. Ozkal, L. G. Bujoreanu, Mechanical cycling effects at Fe-Mn-Si-Cr-Ni SMAs obtained by 
powder metallurgy, Phscs Proc. 10 (2010) 125-131. https://doi.org/10.1016/j.phpro.2010.11.087.

[6] J. L. Proft, T. W. Duerig, T. W. Duerig, K. N. Melton, D. Stockel, C. M. Wayman, Engineering Aspects of Shape Memory Alloys. ButWo-Hei ltd (1990) 115-129. https://doi.org/10.1016/C2013-0-045665.

[7] J. C. Li, M. Zhao, Q. Jiang, Stacking fault energy of iron-base shape memory alloys, Mater. Lett. 38 (1999) 275-277. https://doi.org/10.1016/S0167-577X(98)00172-4.

[8] R.A. Shakoor, F. Ahmad Khalid, K. Kang, Role of samarium additions on the shape memory behavior of iron based alloys, Mater. Sci. Eng. 528 (2011) 2299-2302. https://doi.org/10.1016/j.msea.2010.11.008.

[9] N. Bergeon, S. Kajiwara, T. Kikuchi, Atomic force microscopic study of stressinduced martensite formation and its reverse transformation in a thermo mechanically treated $\mathrm{Fe}-\mathrm{Mn}-\mathrm{Si}-\mathrm{Cr}-\mathrm{Ni}$ alloy, Act Mater. 48 (2000) 4053-4064. https://doi.org/10.1016/S1359-6454(00)00187-7.

[10] H.B. Peng, Y.H.Wen, L.R. Xiong, N. Li, Influence of initial microstructures on effectiveness of training in a $\mathrm{FeMnSiCrNi}$ shape memory alloy, Mater. Sci. Eng. 497 (2008) 61-64. https://doi.org/10.1016/j.msea.2008.06.006.

[11] T.Sawaguchi, L.Bujoreanu, T.Kikuchi, K.Ogawa, M.Koyamaa, M.Murakamic, Mechanism of reversible transformation-induced plasticity of Fe-Mn-Si shape memory alloys, Scr. Mater. 59 (2008) 826-829. https://doi.org/10.1016/j.scriptamat.2008.06.030.

[12]K. Otsuka, C. M. Wayman, Shape Memory Materials, Camb. Uni. Pr. (1999) 117-132.

[13] D.C. Lagoudas, Shape Memory Alloys, Modeling and Engineering Applications, Tex. Uni. (2007) 1-39. https://doi.org/10.1007/978-0387-47685-8.

[14] N.Stanford, D.P.Dunne, Effect of Si on the reversibility of stressinduced martensite in $\mathrm{Fe}-\mathrm{Mn}-\mathrm{Si}$ shape memory alloys, Act. Mater. 58 (2010) 6752-6762. https://doi.org/10.1016/j.actamat.2010.08.041.

[15] R.A. Shakoor, F. Ahmad Khalid, Thermomechanical behavior of Fe$\mathrm{Mn}-\mathrm{Si}-\mathrm{Cr}-\mathrm{Ni}$ shape memory alloys modified with samarium, Mater. Sci. Eng. 499 (2009) 411-414 2009. https://doi.org/10.1016/j.msea.2008.08.042.

[16] N. Bergeon, G. Guenin, C. Esnouf, Microstructural analysis of the stress-induced $\varepsilon$ martensite in a $\mathrm{Fe}-\mathrm{Mn}-\mathrm{Si}-\mathrm{Cr}-\mathrm{Ni}$ shape memory alloy: Part I-calculated description of the microstructure, Mater. Sci. Eng. 242 (1998) 7-86. https://doi.org/10.1016/S09215093(97)00511-X.

[17] N. Stanford, D.P. Dunne, Effect of nitrogen on damping, mechanical and corrosive properties of Fe-Mn alloys, Mater. Sci. Eng. 454 455(2007) 407-415. https://doi.org/10.1016/S0921-5093(02)00060-6.

[18] T. Saito, K. Gąska, A. Takasaki, C. Kapusta, Fabrication of Fe-Mn$\mathrm{Si}$ alloy by mechanical alloying and direct current sintering, J. Meka (2010) $62-67$.
[19] J.S. Benjamin, T.E. Volin, The mechanism of mechanical alloying, Metal. Trans. 5 (1974) 1929-1934. https://doi.org/10.1007/BF02644161.

[20] G. Dowson, Powder Metallurgy, the Process and Its Products, McG. Hil. Publisher. (1990).

[21]C. Suryanarayana, Mechanical Alloying and Milling, Marcel Dekkar, N. Y (2004). https://doi.org/10.1016/S0079-6425(99)00010-9.

[22] A. Akhondzadeh, K. Zangeneh-Madar, S.M. Abbasi, Influence of annealing temperature on the shape memory effect of $\mathrm{Fe}-14 \mathrm{Mn}-$ $5 \mathrm{Si}-9 \mathrm{Cr}-5 \mathrm{Ni}$ alloy after training treatment, Mater. Sci. Eng. 489 (2008) 267-272. https://doi.org/10.1016/j.msea.2007.12.014.

[23] Z. Dong, U.E. Klotz, C. Leinenbach, A. Bergamini, C. Czaderski, M. Motavalli, A Novel Fe-Mn-Si Shape Memory Alloy With Improved Shape Recovery Properties by VC Precipitation, Adv. Eng. Mater. 11 (2009) 40-44. https://doi.org/10.1002/adem.200800312.

[24] A.Baruj, H.E.Troiani, The effect of pre-rolling Fe-Mn-Si-based shape memory alloys: Mechanical properties and transmission electron microcopy examination, Mat. Sci. Eng. 481-482 (2008) 574-577. https://doi.org/10.1016/j.msea.2007.02.140.

[25] N.Stanford, D.P.Dunne, Thermo-mechanical processing and the shape memory effect in an Fe-Mn-Si-based shape memory alloy, Mat. Sci. Eng. 422(2006) 352-359. https://doi.org/10.1016/j.msea.2006.02.009.

[26] O.A.Zambrano, Roland E.Logé, Dynamic recrystallization study of a $\mathrm{Fe}-\mathrm{Mn}$-Si based shape memory alloy in constant and variable thermomechanical conditions, Mat. Char.152 (2019) 151-161. https://doi.org/10.1016/j.matchar.2019.04.016.

[27] A.M.Balagurov, I.A.Bobrikov, J.Pons, J.Cifre, L.Y.Sun, I.S.Golovin, Structure of the Fe-Mn-Si alloys submitted to $\gamma \leftrightarrow \varepsilon$ thermocycling, Mat. Char. 141 (2018) 223-228. https://doi.org/10.1016/j.matchar.2018.04.052.

[28] T. Liu, H.Y. Liu, Z.T. Zhao, R.Z. Ma, T.D. Hu, Y.N. Xie, Mechanical alloying of Fe-Mn and Fe-Mn-Si, Mat. Sci. Eng. 271 (1999) 8-13. https://doi.org/10.1016/S0921-5093(98)01022-3.

[29] Costantino Menna, Ferdinando Auricchio, Domenico Asprone, Applications of Shape Memory Alloys in Structural Engineering, Shape Memory Alloy Engineering, Elsevier. (2015). http://dx.doi.org/10.1016/B978-0-08-099920-3.00013-9.

[30] Amin Charfi, Tarak Bouraoui, Mongi Feki, Chedly Bradai, Bernard Normand, Surface treatment and corrosion behavior of Fe-32Mn-6Si shape memory alloy, C. R. Chimie. 12 (2009) 270-275, http://dx.doi.org/10.1016/j.crci.2007.11.008.

[31] k. Maca, V. Pouchly, A. R. Baccaccini, Sintering Densification Curve - a Practical Approach for Its Construction from Dilatometric Shrinkage Data, Sci. Sinter. 40 (2008) 117-122. https://doi.org/10.2298/SOS0802117M. 